\section{PEMBERDAYAAN DAN PENDAMPINGAN ANAK PUTUS SEKOLAH BERBASIS PEMBELAJARAN KELAS MOTIVASI DAN NON AKADEMIK KOTA SERANG.}

\author{
Rachmi Yulianti ${ }^{1}$, Ahmad Zainuri ${ }^{2}$, Ahmad Sururi $^{3}$ \\ Prodi Administrasi Publik FISIPKUM Universitas \\ Serang Raya
}

*Corresponding author

Email : rachmiyulianti77@gmail.com

\section{Abstraksi}

Tujuan dari pengabdian masyarakat ini adalah pemberian motivasi bagi anak-anak putus sekolah untuk dapat kembali ke sekolah melalui kegiatan pemberdayaan dan pendampingan berbasis pembelajaran kelas motivasi dan non akademik. Metode kegiatan yang digunakan adalah Participatory Learning and Action dengan menekankan pada kegiatan ceramah, diskusi, curah pendapat yang dilakukan secara interaktif dengan anggota kelompok dan dilanjutkan dengan aksi atau kegiatan riil yang relevan dengan materi pemberdayaan masyarakat. Kesimpulan kegiatan pengabdian masyarakat ini adalah ; Anak-anak putus sekolah dapat mengikuti kegiatan dengan baik dan menerima materi pembelajaran meskipun masih perlu dilakukan bimbingan oleh fasilitator dengan tingkat keberhasilan pencapaian kegiatan berada pada kategori $71 \%$ atau skala very good. Rekomendasi dalam kegiatan ini adalah perlunya sinergisitas dengan dinas/instansi terkait agar anak-anak putus sekolah mempunyai kesempatan yang sama dalam mendapatkan akses pendidikan dasar

Kata Kunci : Pemberdayaan dan Pendampingan, anak putus sekolah, pembelajaran non akademik

\section{Abstract}

The purpose of this community service is to provide motivation for school dropouts to be able to return to school through empowerment and mentoring activities based on motivational and non-academic classroom learning. The method of activity used is Participatory Learning and Action by emphasizing lectures, discussions, brainstorming conducted interactively with group members and followed by actions or real activities that are relevant to the community empowerment material. The conclusion of this community service activity is; Out-of-school children can take part in activities well and receive learning material even though it still needs guidance from the facilitator with the success rate of activities being in the $71 \%$ category or very good scale. The recommendation in this activity is the need for synergy with relevant agencies / agencies so that out of school children have equal opportunities to get access to basic education.

Keywords: Empowerment and Mentoring, out of school children, non-academic learning 


\section{PENDAHULUAN}

Pembangunan sumber daya manusia memiliki nilai strategis dan merupakan salah satu modal utama pembangunan sekaligus menjadi faktor penentu kemajuan peradaban suatu bangsa. Fokus pembangunan terhadap sumber daya manusia menjadi pintu masuk bagi suatu negara jika ingin mendorong pembangunan di bidang-bidang lainnya.

Kesadaran dan kemauan dari seluruh pihak termasuk dalam hal ini stakeholder kebijakan pendidikan dasar untuk mempersiapkan sumber daya manusia berkualitas melalui berbagai upaya yang dapat memberikan dampak dan manfaat bagi kehidupan bermasyarakat di masa depan. Dalam hal ini diperlukan sinergisitas antara semua stakeholder kebijakan pendidikan dasar dalam merumuskan, merencanakan dan mengimplementasikan kebijakan pendidikan melalui berbagai upaya yang terintegrasi.

Meskipun demikian, perlu adanya grand design perencanaan pembangunan yang diinisiasi oleh masyarakat lokal maka diharapkan kebutuhan masyarakat terhadap sebuah proses pembangunan akan lebih terakomodir, hal tersebut didasarkan pada kondidi objektif bahwa yang paling tahu dan memahami apa dan bagaimana kebutuhan pembangunan adalah masyarakat itu sendiri (Sururi dan Mulyasih, 2017).

Salah satu upaya yang dapat menjadi faktor pendorong utama dalam membentuk sumber daya manusia berkualitas tersebut adalah kebijakan yang memberikan kemudahan bagi anak-anak usia 7-18 tahun untuk mendapatkan akses pendidikan dasar. Sehingga diharapkan akan memiliki bekal pendidikan dasar yang memadai dan tumbuh menjadi generasi masa depan dengan bekal kemampuan penguasaan ilmu pengetahuan dan teknologi.

Kondisi objektif aspek pendidikan dasar di Kota Serang Provinsi Banten masih terdapat permasalahan anak-anak usia sekolah usia 7-14 tahun yang masih belum dapat menikmati pendidikan dasar sebagaimana mestinya. Tercatat jumlah anak-anak putus sekolah di Kota Serang pada tahun 2018 adalah sekitar 759 anak. Berdasarkan data sistem penanggulangan kemiskinan yang ada di situs resmi Kota Serang, memperlihatkan jumlah anak yang tidak sekolah di Kecamatan Curug sebanyak 43 anak, Kecamatan Walantaka 130 anak, Kecamatan Cipocok Jaya 50 anak, Kecamatan Taktakan 61 anak, Kecamatan Serang 167 anak dan Kecamatan Kasemen 308 anak. Anak-anak yang tidak bersekolah 
tersebut rata-rata pada usia 7-18 tahun. (Kabar Banten, 07 April 2018).

Faktor dominan penyebab tingginya anak-anak putus sekolah tersebut antara lain adalah faktor ekonomi dan sosial (keluarga dan lingkungan). Dampak dari faktor ekonomi tersebut menyebabkan kemampuan sebagian masyarakat tidak mampu membayar biaya sekolah, transportasi, biaya seragam, biaya buku dan pelajaran. Sedangkan faktor sosial menyebabkan anak usia 7-18 tahun tidak memiliki motivasi untuk kembali ke sekolah.

Berdasarkan permasalahan tersebut, tim Pengabdian Masyarakat Program Studi Administrasi Publik Fakultas Ilmu Sosial, Ilmu Politik dan Ilmu Hukum Universitas Serang Raya mengadakan suatu kegiatan pemberdayaan dan pendampingan anak putus sekolah melalui pendekatan yang berbasis pada kelas motivasi dan non akademik di Kota Serang. Pemberdayaan masyarakat dirancang untuk menanggulangi ketertinggalan merupakan bagian dari upaya mempercepat proses perubahan kondisi sosial-ekonomi masyarakat yang masih tertinggal (Sumodiningrat, 1999 dalam Sururi, 2015).

Mitra dalam kegiatan pengabdian masyarakat ini adalah anak-anak putus sekolah yang berjumlah 45 anak dan berasal dari berbagai kelurahan di Kota Serang. Tujuan khusus yang ingin dicapai dalam kegiatan ini adalah memberikan motivasi kepada anak-anak putus sekolah untuk dapat kembali ke sekolah dan memeroleh kesempatan pendidikan dasar secara layak.

\section{METODE PELAKSANAAN KEGIATAN}

Metode yang digunakan adalah Participatory Learning and Action ini dilakukan dengan menekankan pada kegiatan ceramah, diskusi, curah pendapat yang dilakukan secara interaktif dengan anggota kelompok dan dilanjutkan dengan aksi atau kegiatan riil yang relevan dengan materi pemberdayaan masyarakat (Theresia, 2014 dalam Hasanah dan Sururi, 2018). Kegiatan ini dilakukan dengan memberikan fokus dan perhatian pada kegiatan ceramah, praktek simulasi, game play yang dilakukan secara bersama-sama. Secara umum tahapan kegiatan pengabdian ini dapat dilihat pada gambar 1 .

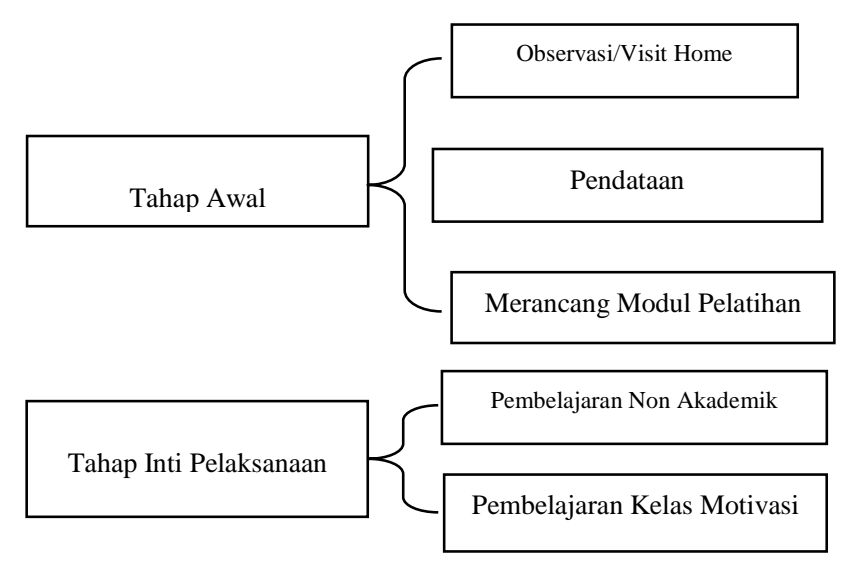

Gambar 1 Bagan Tahapan Kegiatan 
Berikut ini adalah penjelasan pada masingmasing tahap kegiatan.

1. Tahap Awal. Kegiatan pada tahap ini meliputi (a).Observasi Visit Home. Dilakukan sebagai analisis awal untuk mendapat informasi mendalam dan menyeluruh mengenai permasalahan mitra dan mencari solusi yang dibutuhkan dan tepat sasaran; (b).Pendataan dan merancang modul pelatihan yang sesuai dengan kebutuhan mitra dan sebagai solusi dari permasalahan yang dihadapi.

2. Tahap inti/pelaksanaan. Terdiri dari dua tahap yaitu pembelajaran kelas nono akademik dan kelas motivasi.

1. Luaran Per Kegiatan Pendampingan dan Alat Evaluasi

\begin{tabular}{|c|c|c|c|}
\hline \multirow{2}{*}{ Luaran } & \multicolumn{2}{|c|}{ Jenis Evaluasi } & \multirow{2}{*}{ Keterangan } \\
\hline & Angket & Tertulis & \\
\hline $\begin{array}{l}\text { Pembelajaran Non } \\
\text { Akademik } \\
\text { 1. Minat } \\
\text { 2. Respon } \\
\text { 3. Kemauan }\end{array}$ & $\sqrt{ }$ & $\sqrt{ }$ & $\begin{array}{c}\text { Skor } \\
\text { dihitung } \\
\text { dengan } \\
\text { menggun } \\
\text { akan } \\
\text { Penilaian } \\
\text { rata-rata } \\
\text { Excellent: }>80 \%\end{array}$ \\
\hline \begin{tabular}{l}
\multicolumn{2}{l}{ Pembelajaran } \\
Motivasi \\
1. Daya \\
Tanggap \\
2. Mandiri \\
3. $\quad$ Kreativitas
\end{tabular} & $\sqrt{ }$ & $\sqrt{ }$ & $\begin{array}{c}\text { Very good : } \\
70-79 \% \\
\text { Acceptable : } \\
60-69 \% \\
\text { Not Acceptable: } \\
<50 \%\end{array}$ \\
\hline
\end{tabular}

\section{HASIL DAN PEMBAHASAN}

Kegiatan pendampingan ini dilakukan selama 4 (empat) minggu yaitu minggu pertama sampai dengan minggu keempat bulan April 2018.

\section{Tahap Awal}

Pada tahap ini kegiatan observasi dan visit home dilakukan dengan melakukan pengamatan dan kunjungan ke rumah penerima manfaat pengabdian masyarakat dengan tujuan untuk mengetahui dan menganalisis situasi ekonomi, sosial dan lingkungan. Selain itu kegiatan yang dilaksanakan pada minggu pertama dan kedua bulan April 2018 tersebut juga bertujuan untuk melakukan identifikasi potensi dan permasalahan. Kegiatan cross cek lingkungan dilakukan untuk mengetahui akurasi data dengan melakukan wawancara. Hasil survey selanjutnya diolah dengan membuat matrik hasil survey dan wawancara.

\section{Tabel 1}

Hasil Survey dan Analisis Situasi Sosial

\begin{tabular}{|c|l|l|}
\hline No & \multicolumn{1}{|c|}{ Aspek } & \multicolumn{1}{c|}{ Hasil Analisis } \\
\hline 1 & $\begin{array}{l}\text { Terbatasnya } \\
\text { kemampuan } \\
\text { ekonomi }\end{array}$ & $\begin{array}{l}\text { Sebagian besar profesi } \\
\text { masyarakat penerima } \\
\text { manfaat adalah buruh } \\
\text { dan pekerja lepas/free } \\
\text { lance }\end{array}$ \\
\hline 2 & $\begin{array}{l}\text { Situasi } \\
\text { lingkungan } \\
\text { yang kurang } \\
\text { mendukung } \\
\text { pengembangan } \\
\text { kualitas anak }\end{array}$ & $\begin{array}{l}\text { Kawasan permukiman } \\
\text { kumuh dan lingkungan } \\
\text { yang kurang } \\
\text { memberikan } \\
\text { kenyamanan }\end{array}$ \\
\hline
\end{tabular}




\begin{tabular}{|c|l|l|}
\hline 3 & $\begin{array}{l}\text { Rendahnya } \\
\text { motivasi anak } \\
\text { untuk kembali } \\
\text { sekolah }\end{array}$ & $\begin{array}{l}\text { Sebagian besar anak } \\
\text { tidak mau kembali } \\
\text { ke sekolah dan lebih } \\
\text { memilih membantu } \\
\text { orang tua dalam } \\
\text { mencari nafkah }\end{array}$ \\
\hline
\end{tabular}

Sumber : Diolah dari hasil survey, 2018.

\section{Tahap Inti (Kegiatan Pemberdayaan dan Pendampingan)}

Pada tahap ini, kegiatan yang dilakukan adalah terbagi menjadi dua tahap yaitu pembelajaran non akademik dan kelas motivasi. Kegiatan dilakukan pada minggu ketiga dan keempat bulan April 2018. Anakanak putus sekolah ditempatkan di shelter untuk dilakukan pembelajaran non akademik dan bimbingan kelas motivasi.

Tabel 2

Jadwal Pembelajaran

\begin{tabular}{|c|c|c|c|}
\hline No & Kegiatan & Waktu & Ket. \\
\hline 1 & $\begin{array}{l}\text { Perkenalan dan } \\
\text { role game }\end{array}$ & $\begin{array}{c}\text { Minggu } \\
\text { ketiga April } \\
2018\end{array}$ & Tim \\
\hline 2 & $\begin{array}{l}\text { Bimbingan } \\
\text { motivasi dan } \\
\text { pendidikan dasar } \\
\text { (back to school) }\end{array}$ & $\begin{array}{c}\text { Minggu } \\
\text { ketiga April } \\
2018\end{array}$ & Tim \\
\hline 3 & $\begin{array}{l}\text { Pembelajaran non } \\
\text { akademik } \\
\text { Teknik Membaca } \\
\text { Cepat } \\
\text { Tanganku untuk } \\
\text { apa? } \\
\text { Poster Cita-cita } \\
\text { Siapakah Aku? } \\
\text { Sifat Baikku } \\
\text { Iinilah Pendapatku } \\
\text { Keterampilan } \\
\text { Berfikir Kritis } \\
\text { Imagine }\end{array}$ & $\begin{array}{l}\text { Minggu } \\
\text { Ketiga } \\
\text { keempat } \\
2018\end{array}$ & Tim \\
\hline 4 & $\begin{array}{l}\text { Feed back/umpan } \\
\text { balik }\end{array}$ & $\begin{array}{c}\text { Minggu } \\
\text { keempat } \\
\text { April 2018 }\end{array}$ & Tim \\
\hline
\end{tabular}

a) Perkenalan dan Role Game

Kegiatan dilaksanakan di minggu ketiga bulan April 2018 yaitu dari tanggal 02 sampai dengan 03 April 2018. Pada tahap awal ini, anak-anak putus sekolah/penerima manfaat melakukan proses adaptasi terhadap kondisi lingkungan shelter dan teman-teman yang berbeda tempat tinggal. Kegiatan perkenalan dilakukan secara partisipatif dengan mengemukakan asal dan tempat tinggal, alasan mengikuti kegiatan dan penyebab tidak dapat melanjutkan sekolah. Fasilitator yan terdiri dari tim pengabdian masyarakat berperan untuk menciptakan suasana perkenalan berlangsung cair dan dalam suasana gembira.

Kemudian, kegiatan dilanjutkan dengan berbagai permainan dipandu oleh fasilitator. Tujuan kegiatan ini adalah agar anak-anak putus sekolah merasa betah dan kehadirannya dapat diterima oleh semua pihak. Bentuk kreativitas permainan diupayakan dalam suasana kegembiraan dan mampu mendorong rasa nyaman anak-anak putus sekolah untuk dapat melanjutkan ke tahapan kegiatan berikutnya yaitu bimbingan motivasi dan pendidikan dasar.

b) Bimbingan motivasi dan pendidikan dasar (back to school)

Kegiatan dilaksanakan dari tanggal 4 sampai dengan 6 April 2018. Tujuan 
bimbingan motivasi adalah agar anak-anak putus sekolah memiliki motivasi untuk kembali ke sekolah. Pada tahap ini, fasilitator melakukan pendekatan persuasif dengan memberikan pemahaman tentang pentingnya pendidikan untuk masa depan.

Fasilitator berperan menciptakan suasana hati dan fikiran anak-anak putus sekolah untuk kembali bersemangat menempuh pendidikan dasar sebagai bekal di masa yang akan datang. Pendekatan hati ke hati dengan memetakan hambatan-hambatan anak-anak tidak dapat melanjutkan sekolah seperti persoalan ekonomi, sosial dan lingkungan diberikan solusi agar anak-anak tersebut memiliki kemauan yang kuat kembali ke sekolah.

Pada tahap ini, materi kegiatan pendidikan dasar untuk mengulang pembelajaran yang pernah ditempuh dilakukan sesuai dengan tingkat pendidikan anak-anak tersebut. Pembelajaran matematika dasar, bahasa Indonesia dan ilmu pengetahuan kembali diajarkan oleh fasilitator sebagai review dan bekal anak-anak kembali ke jenjang pendidikan.

Tingkat pencapaian pembelajaran motivasi dan pendidikan dasar ditampilkan pada tabel berikut ini :

\begin{tabular}{|l|l|}
\hline \multicolumn{1}{|c|}{ Luaran } & \multicolumn{1}{|c|}{ Outcome } \\
\hline $\begin{array}{l}\text { Tingkat motivasi dan } \\
\text { semangat anak-anak putus } \\
\text { sekolah untuk kembali ke } \\
\text { sekolah }\end{array}$ & $\begin{array}{l}\text { Anak putus sekolah } \\
\text { menjadi termotivasi } \\
\text { kembali ke sekolah }\end{array}$ \\
\hline $\begin{array}{l}\text { Minat dan respon anak- } \\
\text { anak putus sekolah dalam } \\
\text { menerima pembelajaran } \\
\text { pendidikan dasar }\end{array}$ & $\begin{array}{l}\text { Tingkat pencapaian } \\
\text { anak putus sekolah } \\
\text { dalam merespon } \\
\text { pelajaran }\end{array}$ \\
\hline
\end{tabular}

Kemudian dari hasil angket/pertanyaan yang diberikan mengenai minat, respon dan kemauan anak dipaparkan dalam tabel sebagai berikut :

\begin{tabular}{|l|l|}
\hline $\begin{array}{c}\text { Instrumen } \\
\text { Pertanyaan }\end{array}$ & \multicolumn{1}{|c|}{ Hasil } \\
\hline Minat & $\begin{array}{l}31 \text { anak menjawab minat yang } \\
\text { kuat, 9 anak menjawab ragu-ragu } \\
\text { dan 5 anak menjawab tidak } \\
\text { berminat kembali ke sekolah }\end{array}$ \\
\hline Respon & $\begin{array}{l}\text { 34 anak mempunyai respon untuk } \\
\text { kembali ke sekolah dan 11 anak } \\
\text { tidak merespon untuk kembali ke } \\
\text { sekolah }\end{array}$ \\
\hline Kemauan & $\begin{array}{l}\text { 31 anak menjawab mau untuk } \\
\text { kembali ke sekolah, 10 anak } \\
\text { menjawab ragu-ragu dan 4 anak } \\
\text { menjawab tidak mau }\end{array}$ \\
\hline
\end{tabular}

Sumber : Tim Pengabdian Masyarakat, 2019

Dari hasil paparan di atas dapat dijelaskan bahwa untuk instrumen pertanyaan minat, hampir sebagian besar atau 31 anak putus sekolah mempunyai minat yang kuat untuk kembali ke sekolah. Artinya $69 \quad \%$ anak menjawab secara signifikan. Sedangkan untuk instrumen respon sebesar 34 atau $75 \%$ anak putus sekolah merespon secara baik untuk termotivasi kembali sekolah dan untuk 
instrumen kemauan 31 anak atau $69 \%$ mau untuk kembali ke sekolah.

Dengan demikian dapat disimpulkan bahwa dari ketiga instrumen jawaban yang positif diperoleh rata-rata $71 \%$ persen anak termotivasi kembali ke sekolah sedangkan sisanya yaitu $29 \%$ menjawab tidak termotivasi kembali ke sekolah.

c) Pembelajaran non akademik : Teknik Membaca Cepat, Tanganku untuk apa?

Poster Cita-cita Siapakah Aku? Sifat Baikku, Inilah Pendapatku, Keterampilan Berfikir Kritis.

Pada tahap ini, anak-anak putus sekolah diberikan pembelajaran yang dapat memingkatkan aspek-aspek pengetahuan dan keterampilan berfikir. Hal ini bertujuan untuk menstimulus pemikiran anak dan membiasakan pola pendidikan non akademik guna menunjang proses belajar mengajar.

Kegiatan ini berlangsung dinamis, seluruh anak dapat mengikuti kegiatan secara baik dan dapat menunjukkan keterampilan berfikir meskipun masih perlu dilakukan bimbingan. Tingkat pencapaian pada pembelajaran ini menjadi tolok ukur dan penilaian bagi tim pengabdian masyarakat untuk melaksanakan langkah-langkah selanjutnya.

\section{PENUTUP}

\section{1) Kesimpulan}

Dari kegiatan yang telah dilaksanakan, dapat disimpulkan beberapa hal sebagai berikut:

a) Anak-anak putus sekolah dapat mengikuti kegiatan dengan baik dan menerima materi pembelajaran meskipun masih perlu dilakukan bimbingan oleh fasilitator.

b) Tingkat keberhasilan pencapaian kegiatan berada pada kategori $71 \%$ atau skala very good.

\section{2) Rekomendasi}

Rekomendasi dalam kegiatan ini adalah perlunya sinergisitas dengan dinas/instansi terkait agar anak-anak putus sekolah mempunyai kesempatan yang sama dalam mendapatkan akses pendidikan dasar.

\section{REFERENSI}

Hasanah Budi \& Sururi Ahmad, Peningkatan Kapasitas Aparatur Pemerintahan Desa dan Masyarakat melalui Pelatihan Administrasi Pemerintahan di Desa Sukamenak Kecamatan Cikeusal Kabupaten Serang, 2018, e ISSN 25990012, Jurnal Wikrama Prahita LPPM Unsera.

Mardikanto T dan Soebiato P, 2013, Pemberdayaan Masyarakat dalam Perspektif Kebijakan Publik. Alfabeta, Bandung. 
Sururi Ahmad, 2015. Pemberdayaan Masyarakat melalui Program

Pembangunan Infrastruktur Perdesaan dalam Meningkatkan Kesejahteraan Masyarakat Kecamatan Wanasalam Kabupaten Lebak, Jurnal Sawala Administrasi Negara, Volume 3 No. 2, Halaman 1-25.

Sururi, Ahmad dan Mulyasih Rahmi, 2017. Engagement, Jurnal Pengabdian Masyarakat Kopertais IV Surabaya, eISSN 2579-8391 Volume 1 Nomor 2. 